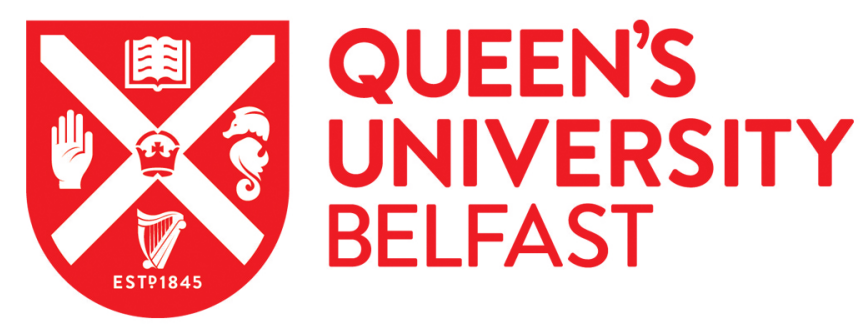

\title{
Interactions between selenium and iodine uptake by spinach (Spinacia oleracea L.) in solution culture
}

Zhu, Y. G., Huang, Y. H., Hu, Y., Liu, Y. X., \& Christie, P. (2004). Interactions between selenium and iodine uptake by spinach (Spinacia oleracea L.) in solution culture. Plant and Soil, 261(1-2), 99-105. https://doi.org/10.1023/B:PLSO.0000035539.58054.e1

Published in:

Plant and Soil

Queen's University Belfast - Research Portal:

Link to publication record in Queen's University Belfast Research Portal

\section{General rights}

Copyright for the publications made accessible via the Queen's University Belfast Research Portal is retained by the author(s) and / or other copyright owners and it is a condition of accessing these publications that users recognise and abide by the legal requirements associated with these rights.

Take down policy

The Research Portal is Queen's institutional repository that provides access to Queen's research output. Every effort has been made to ensure that content in the Research Portal does not infringe any person's rights, or applicable UK laws. If you discover content in the Research Portal that you believe breaches copyright or violates any law, please contact openaccess@qub.ac.uk. 


\title{
Interactions between selenium and iodine uptake by spinach (Spinacia oleracea $\mathbf{L}$.) in solution culture
}

\author{
Yong-Guan Zhu ${ }^{1,3}$, Yizong Huang ${ }^{1}$, Ying $\mathrm{Hu}^{1}$, Yunxia Liu ${ }^{1}$ \& Peter Christie ${ }^{2}$ \\ ${ }^{1}$ Research Center for Eco-environmental Sciences, Chinese Academy of Sciences, Beijing 100085, China. \\ ${ }^{2}$ Department of Agricultural and Environmental Science, Queen's University Belfast, Newforge Lane, Belfast BT9 \\ 5PX, UK. ${ }^{3}$ Corresponding author*
}

Received 26 November 2002; Accepted in revised form 21 May 2003

Key words: human nutrition, iodine, nutrient interactions, plant uptake, selenium

\begin{abstract}
Interactions between Se (as selenate) and I (as iodate) uptake by spinach plants (Spinacia oleracea L.) were studied under controlled conditions using solution culture. Spinach readily accumulated both Se and I in the edible parts, the leaves, with solution-to-leaf transfer factors ranging from 3.5 to 13.4. The distribution coefficients between leaves and roots ranged from 4.07 to 5.66 for I and 4.51 to 8.59 for Se. Selenium concentrations in plant tissues were unaffected by addition of I to the nutrient solution. Similarly, plant I concentrations were unaffected by addition of Se to the nutrient solution, except in nutrient solution with I at a concentration of $50 \mu M$, in which addition of Se lowered shoot I concentrations significantly, but the effect was of low magnitude. These results indicate the possible feasibility of dual supplementation of plant growth substrates with Se and I to improve human nutrition where these two elements are deficient in the diet. The data also indicate the involvement of a positive feedback mechanism in the uptake of Se by spinach plants, since Se concentrations in leaves increased disproportionately with increasing Se concentration in the nutrient solution.
\end{abstract}

\section{Introduction}

Both Se and I are essential trace elements for human health. Selenium has been shown to form part of the important antioxidant enzyme glutathione (GSH) peroxidase (Rotruck et al., 1973). Epidemiological studies have shown that a low intake of Se may increase the risk of cardiovascular disease and even cancer. In China, a low-Se belt was identified in the 1960's stretching from Heilongjiang Province in the northeast to Yunnan Province in the south-west (Wang and Gao, 2001). Selenium deficiency can cause various health problems, such as Keshan and Kaschin-Beck diseases reported in China (Keshan Disease Research Group, 1979; Wang and Gao, 2001). Iodine deficiency disorders (IDD) are believed to be one of the commonest preventable human health problems (Welch and Graham, 1999). It has been estimated that there are

* FAX No:+86-10-6292-3563. Email: ygzhu@mail.rcees.ac.cn about 225 million people worldwide currently affected by I deficiency (goiter), and the population at risk from I deficiency is about 1 billion (World Bank, 1994). Iodine deficiency in China, particularly in western parts of the country, can be severe.

To improve human nutrition of Se and I, supplementation of the diet with the two elements has been practised widely. For I supplementation the most commonly used approach is salt iodination. Although the use of iodized salt has been promoted in China nationwide from the early 1980s, I deficiency remains a major health problem in remote areas such as Xinjiang Province. In these remote regions, I intake by the population is inherently low because there is generally less I in the soil and drinking water than in coastal regions. Iodine deficiency is further exacerbated by two factors. Firstly, the ethnic minority people in Xinjiang prefer the rock salt that is available locally free of charge. Secondly, Chinese cooking methods using oil at high 
temperatures result in the volatilization of I (Zhang et al., 2000). The baking of nan (a major food consumed by the ethnic minorities in Xinjiang) at high temperature (usually around $360^{\circ} \mathrm{C}$ ) is a typical example. A survey in 1999 showed that in Xinjiang about $23 \%$ of children aged between 8 and 10 had goiter (XJDCC, 2000). It is therefore suggested that salt fortification with $\mathrm{I}$ is inadequate as the sole technique employed for the elimination of IDD in most remote regions in China, and that multiple approaches for I fortification in the food chain should be investigated.

Application of Se and I to agricultural soils has been proposed as a useful way to eliminate Se and I deficiencies in the human diet. The first studies on soil application of Se involved the spraying of selenite or selenate solutions on the soil surface (Cary et al., 1967; Watkinson and Davies, 1967). Selenium supplementation to fertilizers in Finland commenced in the mid 1980s and was demonstrated to be effective in improving human Se nutrition (Aro et al., 1998). Iodine supplementation of the food chain has been attempted recently in Xinjiang, for example by the irrigation of paddy soil with iodized water to reduce I deficiency (Cao et al., 1994). This practice has been extended to several prefectures in Xinjiang, and has proved to be a useful approach in reducing I deficiency-related health problems locally (Jiang et al., 1997).

A recent study by Hou et al. (1997) on the dietary intake of I by Chinese people showed that cereals and vegetables are the major sources of I apart from iodinized salt and this also illustrates the importance of I supplementation through the food chain. Previous studies have shown that translocation of I to grains of cereal crops is low because I is relatively immobile in the phloem, while I accumulation in leaves relies mainly on xylem transport. Thus, leafy vegetables might be a good delivery vehicle for I supplementation through the food chain.

Furthermore, the relationship between Se and I is not due simply to dual deficiencies in some locations. There is a close biological relationship between them as three of the iodothyronine deiodinases are selenoenzymes (Arthur et al., 1992). Selenium deficiency in humans can therefore interact critically in I metabolism, leading to an I-unresponsive condition or, even worse, a negative response to I (Hotz et al., 1997). Some recent reports have suggested that Kashin-Beck disease might also be related to I deficiencies as well as Se deficiency (Moreno-Reyes et al., 2001; Zhang et al., 2001). Given the fact that in many parts of China Se and I deficiencies occur together (Tan, 1989), it is
Table 1. Composition of the modified Long Ashton nutrient solution used in this study

\begin{tabular}{cc}
\hline Salt & Solution \\
\hline Macro-nutrients & $\mathrm{m} M$ \\
$\mathrm{KNO}_{3}$ & 4.0 \\
$\mathrm{Ca}\left(\mathrm{NO}_{3}\right)_{2}$ & 4.0 \\
$\mathrm{MgSO}_{4}$ & 1.5 \\
$\mathrm{KH}_{2} \mathrm{PO}_{4}$ & 1.3 \\
$\mathrm{NaCl}$ & 0.1 \\
& \\
$\mathrm{Micro}-\mathrm{nutrients}$ & $\mu M$ \\
$\mathrm{Fe}_{\mathrm{EDTA}}$ & 50 \\
$\mathrm{H}_{3} \mathrm{BO}_{3}$ & 10 \\
$\mathrm{ZnSO}_{4}$ & 1.0 \\
$\mathrm{CuSO}_{4}$ & 1.0 \\
$\mathrm{MnSO}_{4}$ & 5.0 \\
$\mathrm{Na}_{2} \mathrm{MoO}_{4}$ & 0.5 \\
$\mathrm{CoSO}_{4}$ & 0.2 \\
\hline
\end{tabular}

necessary to consider a possible dual supplementation of the two elements in the diet. Both Se and I exist as anions in the environment, and it is unknown if Se and I can interact with each other in plant uptake processes and metabolic processes within plants.

To develop efficient approaches to supplement both Se and I in the food chain in regions where both elements are deficient, it is a prerequisite to understand how and to what extent Se and I interact in plant uptake processes. The objectives of the present study were therefore to investigate the uptake of Se and I by the leafy vegetable crop spinach (Spinacia oleracea L.) with or without the co-existence of the two elements in the growth substrate, and to determine whether there are any significant interactions between the two elements in plant uptake processes.

\section{Materials and methods}

\section{Plant culture}

A hydroponic experiment was carried out in a growth room with a 14-h photoperiod (260-350 $\mu \mathrm{E} \mathrm{m} \mathrm{m}^{-2}$ $\mathrm{s}^{-1}$ ) and a day/night temperature regime of $25 / 18^{\circ} \mathrm{C}$. Seeds of spinach (Spinacia oleracea L.) were disinfected in $10 \%(\mathrm{v} / \mathrm{v}) \mathrm{H}_{2} \mathrm{O}_{2}$ solution for $10 \mathrm{~min}$ followed by thorough washing in deionized water. Seeds were then germinated on moisture filter paper for 2-3 days. 
Geminated seedlings were sown in moist vermiculite, and grew for about 10 days to the four-leaf stage. After the initial growth period in the seedbed, seedlings were carefully removed and were thoroughly washed free of any adhering particles under tap water. Seedlings were then transferred to PVC pots $(7.5 \mathrm{~cm}$ diameter $\times 15 \mathrm{~cm}$ in height) containing $500 \mathrm{~mL}$ nutrient solution with continuous aeration. Modified Long Ashton nutrient solution was used (Table 1). Three concentrations $(0,10$ and $50 \mu M)$ of both I (as iodate) and Se (as selenate) were used, giving a total of nine treatments with four replicates of each treatment. Plants were grown for 21 days in the nutrient solution. Nutrient solution was changed twice a week, and solution $\mathrm{pH}$ was adjusted to 6.0 using dilute $\mathrm{HCl}$ or $\mathrm{KOH}$ solutions. At the termination of the experiment, plant roots were washed in deionized water and blotted dry. Plants were divided into roots and shoots (leaves), and fresh weights were determined immediately after harvest. Plant materials were then oven dried at $70^{\circ} \mathrm{C}$ for 72 $\mathrm{h}$, and dry weights were determined for all tissues. Tissues were all ground for Se and I analysis.

\section{Iodine analysis}

Dried plant samples and reference materials (80$150 \mathrm{mg}$ per sample) were double sealed in a polyethylene bag for irradiation. Each sample was irradiated for $15 \mathrm{~min}$ in a nuclear reactor developed by the Chinese Institute of Nuclear Science in Beijing. The thermal neutron flux used was $8.0 \times 10^{11} \mathrm{n} \mathrm{cm}^{-2} \mathrm{~s}^{-1}$. In the irradiation facility, samples were shielded in a BN (nitride boron) box.

${ }^{128}$ I was determined by $\gamma$-ray analysis using highresolution $\mathrm{Ge}(\mathrm{Li})$ detectors (Ortec, USA) for $10 \mathrm{~min}$ at $442.9 \mathrm{keV}$. Analytical accuracy, measured using the reference material, was between 2 and $6 \%$.

\section{Se analysis}

Dried plant samples and reference material $(50 \mathrm{mg}$ per sample) were double sealed in a polyethylene bag for irradiation. Each sample was irradiated for about $1 \mathrm{~min}$ in a nuclear reactor developed by the Chinese Institute of Nuclear Science in Beijing. The thermal neutron flux used was $2.5 \times 10^{11} \mathrm{n} \mathrm{cm}^{-2} \mathrm{~s}^{-1} \cdot{ }^{77 m} \mathrm{Se}$ (half life $17.5 \mathrm{~s}$ ) was determined by $\gamma$-ray analysis using high-resolution Ge(Li) detectors (Ortec, USA) for $10 \mathrm{~s}$ to $1 \mathrm{~min}$ at $161 \mathrm{keV}$. Analytical accuracy, measured using the reference material, was about $4 \%$.
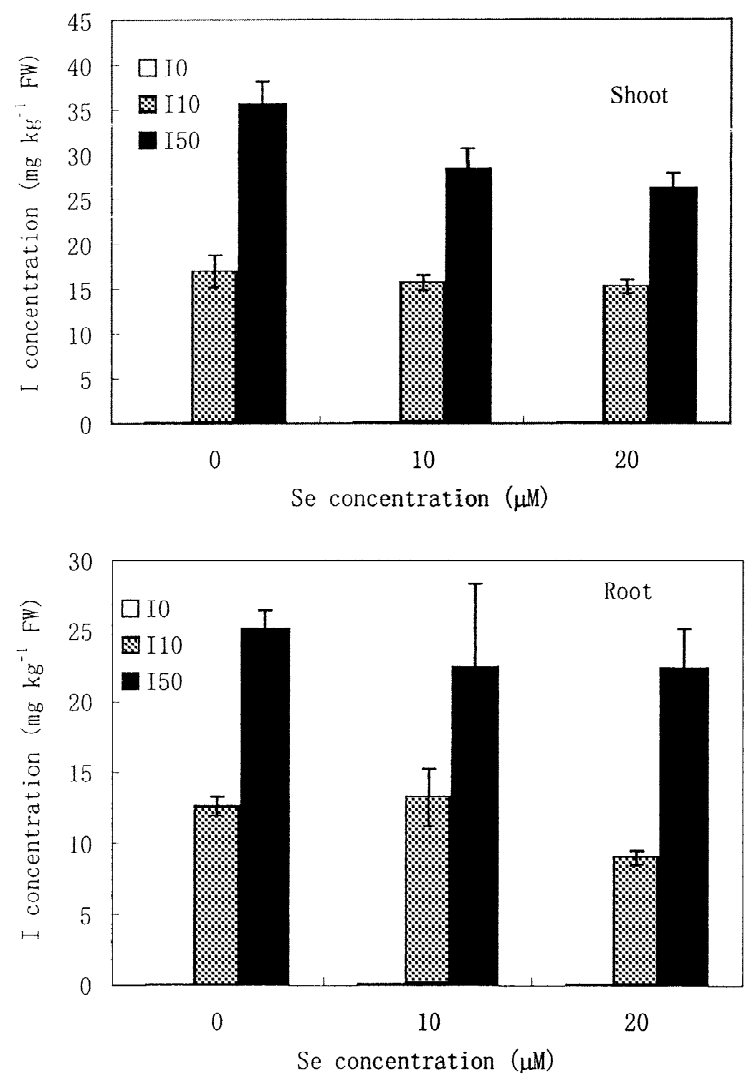

Figure 1. Iodine concentrations in shoot and root tissues of spinach plants grown in solution culture with different concentrations of Se and I. Bars: standard error.

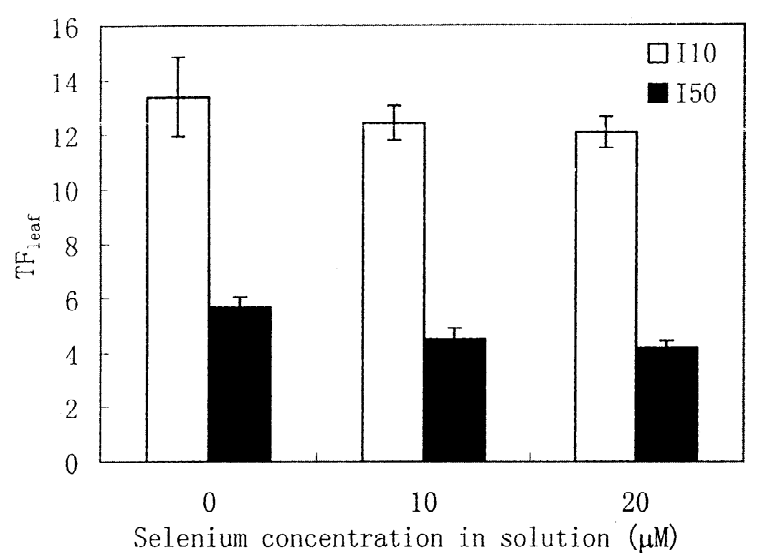

Figure 2. Solution-to-leaf transfer factors for I in spinach plants grown at different Se and I concentrations in solution culture. Bars: standard errors.

\section{Data analysis}

Se and I concentrations $\left(C_{\text {plant }}\right)$ in leaves and roots were calculated both on fresh and dry weight basis. 
Solution-to-leaf transfer factors $\left(\mathrm{TF}_{\text {leaf }}\right)$ were calculated as follows:

$$
\mathrm{TF}_{\text {leaf }}=\left[\mathrm{C}_{\text {leaf }}\right]_{\text {fresh }} / C_{\text {solution }},
$$

where $\left[\mathrm{C}_{\text {leaf }}\right]_{\text {fresh }}$ is leaf Se or I concentration on fresh weight basis, and $\mathrm{C}_{\text {solution }}$ is the corresponding solution concentration of Se or I.

Distribution coefficients (DC) of Se and I are defined as the ratio of the total Se or I in leaves to that in roots.

All data were subjected to two-way analysis of variance (ANOVA) performed using the Microsoft Windows-based Genstat package (6th edition, NAG Ltd, England).

\section{Results}

\section{Plant biomass}

Table 2 shows the root and shoot biomass of spinach plants grown in solution culture at different concentrations of Se and I. Root biomass was significantly affected by I and Se concentrations in the growth solution. With no I addition, root biomass at a Se concentration of $10 \mu M$ was significantly lower than at Se concentrations of 0 and $20 \mu M$. At an I concentration of $10 \mu M$, root biomass was unaffected by Se concentration. At an I concentration of $20 \mu M$, addition of Se significantly reduced root biomass. Addition of I reduced root biomass at an Se concentration of $20 \mu M$. Selenium addition at the selected concentrations had no significant effect on plant shoot biomass, but our preliminary results (data not shown) showed that a Se concentration of $50 \mu M$ reduced shoot biomass substantially. Addition of I tended to reduce plant shoot biomass when Se was also added, indicating an interaction between I and Se (Table 2).

\section{I accumulation in plant tissues}

Concentrations of I in roots and shoots on a fresh weight basis increased significantly with increasing nutrient solution I concentration (Figure 1). A trace amount of I was detected in plants grown in solution with no I addition, indicating that the plants may have acquired I from the atmosphere by foliar absorption. At an I concentration of $50 \mu \mathrm{M}$ in the growth solution, the addition of Se slightly inhibited the accumulation of $\mathrm{I}$ in the shoots $(P<0.05)$, but not in the roots (Figure 1). $\mathrm{TF}_{\text {leaf }}$ values for I varied from about 4 to
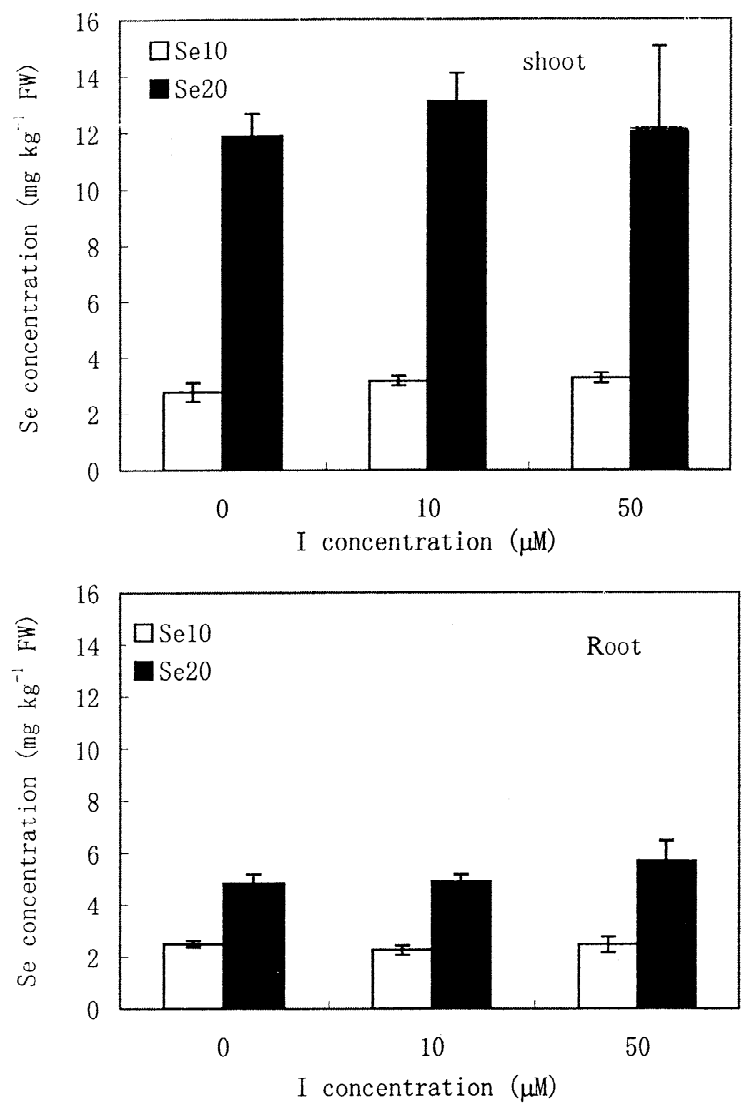

Figure 3. Se concentrations in shoots and roots of spinach plants grown in solution culture with different Se and I concentrations. Bars: Standard error.

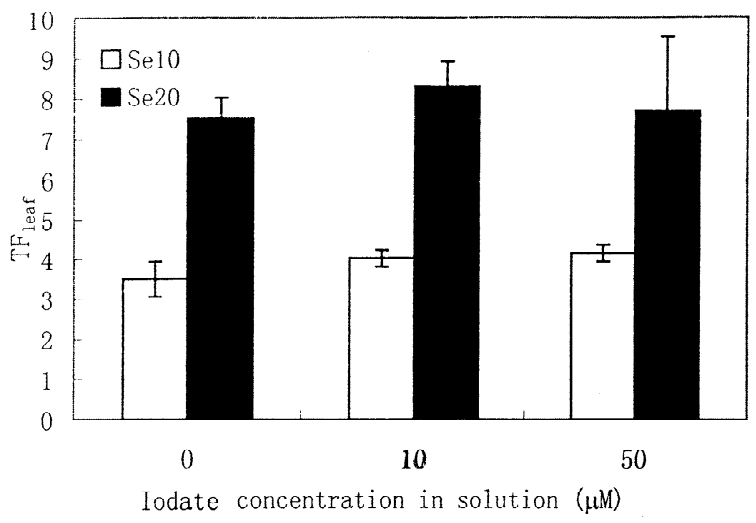

Figure 4. Solution-to-leaf transfer factors for Se in spinach plants grown in solution culture with different concentrations of Se and I. Bars: Standard error.

13 (Figure 2$)$, and decreased significantly $(P<0.001)$ with increasing solution I concentration. 
Table 2. Biomass of spinach plants grown in different I and Se concentrations in solution culture $\left(\mathrm{g} \mathrm{pot}^{-1}\right.$, dry matter basis)

\begin{tabular}{|c|c|c|c|c|c|c|}
\hline \multirow{3}{*}{$\begin{array}{l}\text { I concentration } \\
\qquad(\mu \mathrm{M})\end{array}$} & \multicolumn{3}{|c|}{ Shoot } & \multicolumn{3}{|c|}{ Root } \\
\hline & \multicolumn{6}{|c|}{ Se concentration in the solution $(\mu \mathrm{M})$} \\
\hline & 0 & 10 & 20 & 0 & 10 & 20 \\
\hline \multirow[t]{2}{*}{0} & 2.94 & 2.29 & 3.07 & 0.88 & 0.47 & 0.96 \\
\hline & $(0.11)^{*}$ & $(0.22)$ & $(0.16)$ & $(0.09)$ & $(0.01)$ & $(0.07)$ \\
\hline \multirow[t]{2}{*}{10} & 2.30 & 2.68 & 1.81 & 0.55 & 0.61 & 0.43 \\
\hline & $(0.19)$ & $(0.05)$ & $(0.23)$ & $(0.06)$ & $(0.08)$ & $(0.06)$ \\
\hline \multirow[t]{3}{*}{50} & 2.85 & 1.94 & 2.23 & 0.75 & 0.45 & 0.52 \\
\hline & $(0.41)$ & $(0.28)$ & $(0.04)$ & $(0.11)$ & $(0.09)$ & $(0.01)$ \\
\hline & \multicolumn{6}{|c|}{ Analysis of variance } \\
\hline Iodine (I) & \multicolumn{3}{|c|}{$P<0.050$} & \multicolumn{3}{|c|}{$P<0.001$} \\
\hline Selenium (Se) & \multicolumn{3}{|c|}{ NS } & \multicolumn{3}{|c|}{$P<0.010$} \\
\hline $\mathrm{I} \times \mathrm{Se}$ & \multicolumn{3}{|c|}{$P<0.010$} & \multicolumn{3}{|c|}{$P<0.010$} \\
\hline $\mathrm{LSD}_{0.05}$ & \multicolumn{3}{|c|}{0.65} & \multicolumn{3}{|c|}{0.21} \\
\hline
\end{tabular}

* Data in brackets represent the standard error.

Table 3. Distribution coefficients (DC) of Se and I between shoots and roots of spinach plants grown in solutions with different concentrations of Se and I $(\mu M)$

\begin{tabular}{|c|c|c|c|c|c|c|}
\hline \multirow[t]{3}{*}{ Se concentration } & \multicolumn{3}{|c|}{$\mathrm{DC}$ for $\mathrm{Se}$} & \multicolumn{3}{|c|}{ DC for I } \\
\hline & \multicolumn{6}{|c|}{ I concentration } \\
\hline & 0 & 10 & 50 & 0 & 10 & 50 \\
\hline 0 & $\mathrm{NA}^{*}$ & NA & NA & NA & $\begin{array}{c}4.41 \\
(0.42)\end{array}$ & $\begin{array}{c}5.66 \\
(0.72)\end{array}$ \\
\hline 10 & $\begin{array}{c}4.51 \\
(0.38)^{* *}\end{array}$ & $\begin{array}{c}5.02 \\
(0.47)\end{array}$ & $\begin{array}{c}5.46 \\
(0.35)\end{array}$ & NA & $\begin{array}{c}4.37 \\
(0.52)\end{array}$ & $\begin{array}{c}4.07 \\
(0.45)\end{array}$ \\
\hline \multirow[t]{2}{*}{20} & $\begin{array}{c}6.30 \\
(0.16)\end{array}$ & $\begin{array}{c}8.59 \\
(1.74)\end{array}$ & $\begin{array}{c}6.69 \\
(1.08)\end{array}$ & NA & $\begin{array}{c}4.49 \\
(0.82)\end{array}$ & $\begin{array}{c}4.30 \\
(0.39)\end{array}$ \\
\hline & \multicolumn{6}{|c|}{ Analysis of variance } \\
\hline $\mathrm{Se}$ & & $P=0.008$ & & & NS & \\
\hline I & & NS & & & NS & \\
\hline $\mathrm{Se} \times \mathrm{I}$ & & NS & & & NS & \\
\hline
\end{tabular}

* NA, not applicable because no I or Se were added to the solution.

** Data in brackets represent the standard errors.

\section{Selenium accumulation in plant tissues}

Concentrations of Se in shoots and roots on a fresh weight basis increased dramatically with increasing solution Se concentration (Figure 3). No Se was detected in tissues of plants grown in solution with no Se. Iodine concentrations in the solution had no significant effect on Se concentrations in plant tissues. $\mathrm{TF}_{\text {leaf }}$ values for Se varied from 3.5 to about 8.3 (Figure 4). Unlike I, $\mathrm{TF}_{\text {leaf }}$ values for Se increased significantly
$(P<0.001)$ with an increasing solution Se concentration, and were unaffected by the addition of I to the solution.

\section{Discussion}

Although it is widely recognized that $\mathrm{Se}$ and I are closely related biologically in animals (Arthur et al., 1992), interactions between Se and I in plant uptake 
processes have rarely been reported in the literature. Results from the present study show that at high concentrations of I in the growth solution, addition of Se slightly (but significantly) depressed the I concentration in plant tissues, but this effect was only marginal (Figure 1). These results clearly show that there were no strong interactions between Se and I in plant uptake processes and metabolism, implying that dual supplementation of Se and I in soil-plant systems may be feasible.

Previous studies on plant uptake have been mainly concerned with soils contaminated with Se and the potential for phytoremediation of these contaminated soils (Terry et al., 2000) and phytovolatilization (Zayed et al., 1998). The principal aim of this study was to investigate the feasibility of dual fortification (or supplementation) of both Se and I in the human food chain. Selenate is believed to be taken up by plant roots through a sulphate transport in the root plasma membrane (Abrams et al., 1990; Arvy, 1993), and therefore $\mathrm{SeO}_{4}{ }^{2-}$ can compete with $\mathrm{SO}_{4}{ }^{2-}$. It has been shown that sulphate salinity drastically inhibits plant uptake of selenate (Bell, et al., 1992; Mikkelen et al., 1988; Wu and Huang, 1991). Chloride salinity has been observed to have much less effect on selenate uptake than sulphate salinity (Mikkelen et al., 1988; Shennan et al., 1990; Wu and Huang, 1991). Results from this study indicate that there is no inhibitory effect of I (as iodate) on plant uptake of selenate, suggesting that plant uptake of iodate is unlikely to be mediated by the selenate uptake system on the plant root plasma membrane. The observation that Se accumulation in plant tissue increased disproportionately with increasing Se concentration in the growth solution (see Figure 4) is interesting, and may indicate the occurrence of positive feedback control of Se uptake by spinach plants. A similar phenomenon was demonstrated by Wu et al. (1988) in some grass species. The physiological mechanisms behind this disproportionality are unknown.

In terms of Se and I supplementation of human diets for enhanced nutrition, the accumulation of these two elements in edible parts of plants is very important. Results from this study show that both Se and I are accumulated mainly in the leaves, with shoot-toroot distribution coefficients (DC) for Se and I ranging from 4.07 to 8.59 (Table 3). It has been shown that Se can be easily translocated from roots to shoots if plants are fed with selenate (Zayed et al., 1998). The DC values for Se obtained in this study are comparable to those reported by Zayed et al. (1998), and the
DC values for I are comparable to those we reported earlier in solution culture (Zhu et al., 2003). In this study the concentrations of Se and I in the growth solution were much higher than would be conventionally found in arable soils. Nevertheless, according to the $\mathrm{TF}_{\text {leaf }}$ values obtained in this study, we suggest that concentrations of Se and I of less than $1 \mu M$ in the growth solution (or soil solution) would be sufficient for supplementation of the human diet with these two elements.

\section{Acknowledgements}

This study is financially supported by the 'Hundred Talent' program and a Knowledge Innovation Program (KIP) key project from the Chinese Academy of Sciences (KZCX1/SW/19).

\section{References}

Abrams M M, Shennan C, Zasoski R J and Burau R G 1990 Selenomethionine uptake by wheat seedlings. Agron. J. 82, 1127-1130.

Aro A, Alfthan G, Ekholm P and Varo P 1998 Effects of selenium supplementation of fertilizers on human nutrition and selenium status. In Environmental Chemistry of Selenium. Eds. W T Frankenberger and R A Engberg. pp. 81-97. Marcel Dekker, New York.

Arthur J R, Nicol F and Beckett G J 1992 The role of selenium in thyroid hormone metabolism and effects of selenium deficiency on thyroid hormone and iodine metabolism. Biol. Trace Elem. Res. 34, 321-325.

Arvy MP 1993 Selenate and selenite uptake and translocation in bean plants (Phaseolus vulgaris). J. Exp. Bot. 44, 1083-1087.

Bell P F, Parker D R and Page A L 1992 Contrasting selenate sulfate interactions in selenium-accumulating and nonaccumulating plant species. Soil Sci. Soc. Am. J. 56, 1818-1824.

Cary E E, Wieczorek G A and Allaway W H 1967 Reactions of selenite-selenium added soils that produce low selenium forage. Soil Sci. Soc. Am. Proc. 31, 21-26.

Cao X Y, Jiang X M, Kareem A, Dou Z H, Rakeman M A, Zhang M L, Ma T, O’Donnell K, Delong N and Delong G R 1994 Iodination of irrigation water as a method of supplying iodine to a severely iodine-deficient population in Xinjiang, China. Lancet 344, 107-109.

Hotz C S, Fitzpatrick D W, Trick K D and L'Abbe R 1997 Dietary iodine and selenium interact to affect thyroid horme metabolism of rats. J. Nutr. 127, 1214-1218.

Hou X L, Chai C F, Qian Q F, Liu G D, Zhang Y B and Wang K 1997 The study of iodine in Chinese total diets. Sci. Total Environ. 193, 161-167.

Jiang X M, Cao X Y, Jiang J Y, Ma T, James D W, Rakeman M A, Mamette M, Amette K, Zhang M L and Delong G R 1997 Dynamics of environmental supplementation of iodine: Four-years' experience of iodination of irrigation water in Hotien, Xinjiang province, China. Arch. Environ. Health 52, 399-408. 
Keshan Disease Research Group 1979 Epidemiologic studies on etiologic relation of selenium and Keshan disease. Chin. Med. J. 92, 477-482.

Mikkelen R L, Page A L and Haghnia G H 1988 Effect of salinity and its composition on the accumulation of selenium by alfalfa. Plant Soil 107, 63-67.

Moreno-Reyes R, Suetens C, Mathieu F, Begaux F, Zhu D, Rivera T, Boelaert M, Neve J, Perlmutter N and Vanderpas J 2001 KashinBeck disease and iodine deficiency in Tibet. Int. Orthopaed. 25, 164-166.

Rotruck J T, Pope A L, Ganther H E, Swanson A B, Hafeman D G 1973 Selenium: biochemical role as a component of gluthathione peroxidase. Science 179, 588-590.

Shennan C, Schachtman D P and Cramer G R 1990 Variation in selenium-75-labelled selenate uptake and partitioning among tomato cultvars and wild species. New Phytol. 115, 523-530.

Tan J A 1989 Atlas of Endemic Diseases and their Environments in the People's Republic of China. Science Press, Beijing.

Terry N, Zayed A M, de Souza M P and Tarun AS 2000 Selenium in higher plants. Annu. Rev. Plant Physiol. Plant Mol. Biol. 51, 401-432.

Wang Z J and Gao Y X 2001 Biogeochemical cycling of selenium in Chinese environments. Appl. Geochem. 16, 1345-1351.

Watkinson J H and Davies E B 1967 Uptake of native and applied selenium by pasture species. III. Uptake of selenium from various carriers. N. Z. J. Agric. Res. 10, 116-121.

Welch R M and Graham R D 1999 A new paradigm for world agriculture: meeting human needs - productive, sustainable, nutritious. Field Crops Res. 60, 1-10.
World Bank 1994 The challenge of dietary deficiencies of vitamins and minerals. In Enriching Lives: Overcoming Vitamin and Mineral Malnutrition in Developing Countries. pp. 6-13. World Bank, Washington, DC.

Wu L and Huang Z Z 1991 Chloride and sulfate salinity effects on selenium accumulation by tall fescue. Crop Sci. 31, 114-118.

Wu L, Huang Z Z and Burau G R 1988 Selenium accumulation and selenium-salt cotolerance in five grass species. Crop Sci. 28, 517-522.

Xinjiang Disease Control Centre (XJDCC) 2000 Survey report of iodine deficiency disorders in Xinjiang Province, China, in 1999. Endemic Dis. Bull. 15, 59-63.

Zayed A, Lytle C M and Terry N 1998 Accumulation and volatilization of different chemical species of selenium by plants. Planta 206, 284-292.

Zhang L, Chen Z, Wang J and Bao J 2000 Iodine loss from iodinated salt during processing, sale and consumption. Zhejiang Prevent. Med. 12, 32-34.

Zhang W H, Neve J, Xu J P, Vanderpas J and Wang Z L 2001 Selenium, iodine and fungal contamination in Yulin District (People's Republic of China) endemic for Kashin-Beck Disease. Int. Orthopaed. 25, 188-190.

Zhu Y G, Huang Y Z, Hu Y and Liu Y X 2003 Iodine uptake by spinach (Spinacia oleracea $\mathrm{L}$.) plants grown in solution culture: effects of iodine species and solution concentrations Environ. Int. 29, 33-37. 